\section{The end of the National Health Service}

\author{
John Launer
}

Earlier this year, the National Health Service in England was abolished in its previous form and replaced by a commissioning system. Following the Health and Social Care Act, the secretary of state for health gave up direct responsibility for the provision of the nation's health services, passing these over to a commissioning board. ${ }^{1}$ Primary care trusts-the public bodies that formerly provided some health care directly and commissioned the rest-also went. In their place, the government set up local clinical commissioning groups, subject to regulations compelling them to put most if not all service provision out for competitive tender. In the few months since the legislation came into force, the large majority of tenders have in fact been awarded to private companies. Although the term National Health Service and the NHS brand continue to be used, a National Health Commissioning System or NHCS is in fact a more correct term. What was largely a public service is being replaced by a network of public, private and charitable services, still funded mainly through taxation but each operating independently.

Not surprisingly, there have been heated political debates about these changes, but my purpose in the article is not to give an account of these. Instead, I want to offer some reflections from the perspective of a clinician and educator who was born a year after the National Health Service was founded in 1948, qualified in 1978 at almost the mid-point in its history, and approaches retirement around the time of its dissolution as a managed service in 2013.

The first and perhaps the most obvious point to make is that these changes represent a significant turning point in the social, political and cultural history of England. For everybody of my generation-not only health professionals but almost the entire population-a free, public funded and nationally managed health service was part of the definition of what it meant to live in England and to be English. At the time I qualified and for very many years afterwards, the NHS was almost universally described as 'the best in the world'. Even when this claim became contestable in terms of clinical outcomes, virtually every

Correspondence to Dr John Launer, Faculty Development, Shared Services, Health Education, Stewart House, 32 Russell Square, London WC1B 5DN, UK: john.launer@southlondon.hee.nhs.uk informed person across the world still praised its principles and mode of operation as the fairest and most efficient that could be imagined. What everyone regarded as our key national institution no longer exists in the form it did.

\section{NATURAL EXPERIMENT}

The next point worth making is that the Health and Social Care Act does not actually apply to all of the UK. The devolved nations-Scotland, Wales and Northern Ireland-were not covered by the act. Around half the area of the UK will continue to have the NHS in its traditional form, run from regional offices. The changes have therefore set in motion a natural experiment, with two radically different health systems co-existing within one sovereign state. This may accelerate the process by which the state itself divides into two or more independent nations.

Given the effects on national identity and cohesion, one could be forgiven for taking the view that the UK government blundered into such action by accident. Indeed, quite a number of people hold a belief of this kind. However, even a brief review of the history of the NHS in the 65 years from start to finish shows that the changes are part of a clear ideological pattern. The NHS arose as the consequence of victory over fascism in the second world war, and the desire to make Britain a fairer country. It was inspired by the socialism of prime minister Clement Atlee, and backed by the prophet of welfare economics, John Maynard Keynes. Its reversal began in the 1980 s with victory over communism in the Cold War and the desire to make Britain a more competitive country. This was inspired by a passionate belief in capitalism held by prime minister Margaret Thatcher, backed by the prophet of market economics, Milton Friedman. It was Mrs Thatcher who first introduced the rhetoric and apparatus of the market into health care, with an explicit split between 'purchasers' and 'providers'. Since then, every government, of whatever party, has continued to travel in the same direction. Successively, they have all brought in measures that have drawn more private capital into the health service and created more private profits.

For any reasonably prescient observer of national and global trends, the question has not been whether we would reach the tipping point of denationalisation, but when and how quickly this would happen. The historical context may help to explain some peculiar features that many people have observed in the recent NHS reforms. For example, neither of the parties in the government coalition ever declared any intention to bring about this radical and final split with the past. In a sense they did not need to, since the ground had already been laid so effectively over so many years. Equally, the more or less total lack of any interest in these events by the media, and the tacit public acceptance of the changes, are of a piece with the history.

When patients are already used to seeing hospitals boost their income by renting space in the foyer to Starbucks or Burger King, it will not seem too shocking when they attend clinics run by Serco or Virgin, especially if the familiar logo of the NHS still appears on the signs. The words privatisation or denationalisation are not actually being used by those who have put the changes into effect. There has also been some obfuscation, so that a simple ideological shift was packaged as an immensely long and complicated piece of legislation with a host of additional regulations. However, the fact is that capitalism has now won hands down.

\section{SOCIAL INEQUALITIES}

Along with many if not most of my generation, I feel as if the NHS has been in my bones and my bloodstream. Like others, I have been alarmed by how little attention the reforms have paid to social inequalities and their effects on health, and also by the emphasis that private providers are placing on profit at the expense of jobsnot to mention the risks of the same inefficiencies and injustices that characterise the money-driven health system in the US. At the same time, I do not believe the reforms have been driven entirely by venality or self-interest. Although these factors have played their part, the changes have mainly been driven by a set of beliefs I do not happen to share, but which I recognise has its own compelling logic: that large scale private enterprise creates wealth and a better quality of life for a great many people, and it is worth tolerating the tremendous disparity in incomes and health between the powerful and super-rich on the one hand and the severely deprived on the other because of this.

Like most commentators, I do not think the trajectory towards privatisation of the English health service has reached its conclusion, or anything like it. I am fairly sure we will see payments introduced for 
some consultations and services, while a variety of other services will no longer be commissioned at all. In addition, I expect to hear about hybrid models of payment including the possibility of upgrading from free provision to better clinical services funded through additional fees or insurance.

However I am equally sure this will not be the end of the story. Every political and economic system contains the weaknesses that eventually lead to its own destruction. Those of us who lived through much of our careers expecting the NHS and its values to be unassailable have learned this principle to our cost. Those who proclaim the irreversible triumph of the market will sooner or later be in for an equally unpleasant surprise. The consequences of trying to replace the NHS with a fragmented, profit-based system are already beginning to hit the headlines. In the end, the National Health Commissioning System may turn out to be rather more transitory than the service it has just replaced.
Competing interests None.

Provenance and peer review Commissioned; internally peer reviewed.

To cite Launer J. Postgrad Med J 2013;89:613-614.

Postgrad Med J 2013;89:613-614.

doi:10.1136/postgradmedj-2013-132340

\section{REFERENCE}

1 The changing NHS. BBC News, 1 Mar 2013. http:// www.bbc.co.uk/news/health-19674838 (accessed 26 Aug 2013). 